\title{
THE EFFICIENCY OF SOME ACTIVITIES FOR THE DEVELOPMENT OF URBAN INFRASTRUCTURE FOR PUBLIC TRANSPORT, CYCLISTS AND PEDESTRIANS
}

\author{
DMITRII ZAKHAROV \& ALEXEY FADYUSHIN \\ Department of Road Transport Operation, Industrial University of Tyumen, Russia
}

\begin{abstract}
The article overviews the influence transport supply has on the functioning parameters of the urban mobility structure of a large city that does not have off-street transport. The influence of the cost of paid parking, the length of bus and bike lanes on the share of trips by personal and public transport, cycling and pedestrian traffic is established. An assessment of the change in passenger traffic at individual bus stops and passenger traffic on bus routes is carried out with a change in the structure of urban mobility. The change in urban mobility with the expansion of the paid parking zone in the city centre is considered. The structure of urban mobility is determined using simulation modelling with a macroscopic transport model of a large city with a population over 800 thousand people. The parameters of threefactor mathematical models are determined, the adequacy of the models are checked and the static characteristics are presented. Changes in routes of movement of pedestrians and passengers of public transport after the construction of a new pedestrian bridge are predicted. Pedestrian traffic on the bridge increases with the introduction of a bus stop next to the bridge and two new routes for public transport. Keywords: bike lanes, bus lane, paid parking, pedestrian traffic, transport planning and modelling, urban mobility, urban transport system
\end{abstract}

\section{INTRODUCTION}

Cities in Europe, North America, and Russia compete with each other for human potential and try to increase their competitiveness by creating a comfortable urban environment. Reducing the loss of time for movement is one of the important measures to create a comfortable urban environment. In the second half of the 20th century, Europe and America dealt with this problem by motorization. Realizing the futility of this path, for the last 20-30 years the municipal authorities have been developing public transport and stimulating traveling by bicycle and on foot. In Russia, the development of urban transport systems follows the foreign route with a lag of 20-30 years. Cities in emerging economies are experiencing difficulties in developing transport systems. With an increase in the number of residents, large cities receive not only competitive advantages in the economy, but also problems with ensuring sustainable mobility of citizens [1-4] and air pollution with exhaust gases from cars [5].

A trend of the recent decade in the development of urban transport systems has been the implementation of a set of measures within the framework of the 'Mobility as a service' (MaaS) concept. When the MaaS concept is introduced in cities, the structure of population mobility is predicted based on macroscopic simulation in the PTV MaaS Modeller software program developed on the basis of the PTV Visum program. The static model will take into account unmanned vehicles, taxi services, car sharing and bicycle sharing, dynamic (changing in space and time) bus routes [6]. Globally, the development of sustainable urban mobility includes creating priority conditions for public transport and cyclists in comparison with the use of a private car [7-12] and the formation of demand for travel by public transport by a set of socio-economic and political measures. To reduce the number of trips by private vehicles in many cities of the world and the Russian Federation, the number of parking lots is reduced and payment for parking of personal vehicles is introduced [13-16]. 
The structure of transport demand by means of transport and transportation methods is the result of the choice of people when making a decision to move around the city [17-19]. To study the reasons and conditions influencing the choice, it is necessary to establish a model of transport behaviour. Research in this area has found wide application in many countries and cities [20,21].

The transport behaviour model both influences and depends on the urban transport system. System operation parameters (average vehicle speed, correspondence time, ride comfort and safety) affect the choice of the city residents' method of travel. When a resident of the city changes the way of movement, the parameters of the functioning of the transport system change [22].

The structure of urban mobility depends on the weather, climatic, transport and road conditions of vehicle operation and socio-demographic, geographical and economic factors. The structure of urban mobility in different cities of the world differs significantly [23]. The level of development of the transport infrastructure has a significant impact on the distribution of demand by means of transport and methods of transportation. Each city has its own optimal structure of transport mobility, at which the balance and stability of the transport system are achieved [24]. With an imbalance in transport demand and supply, the time for correspondence increases, and the quality of transport services for the population of cities decreases [25].

The spread of Coronavirus Covid-19 in 2020 has had a significant impact on urban transport systems. During the period when restrictions on the movement and operation of enterprises were introduced, the transport system was subjected to significant impacts. The number of passengers in public transport during this period decreased by two times [26].

The aim of this work is to establish the influence the development of infrastructure for public transport, cycling and parking space has on the structure of urban mobility in cities.

\section{MATERIALS AND METHODS}

A major challenge for urban transport systems is the worldwide spread of Coronavirus Covid-19 in the first half of 2020. In many cities around the world, the authorities, without waiting for the end of the pandemic, have begun to modernize the transport infrastructure of cities: increasing the length of bike lanes and expanding pedestrian sidewalks. Russian transport planning experts predict a decrease in demand for public transport in the short and medium terms due to fear of contracting the virus and an increase in demand for walking and cycling. According to statistics, the number of new bicycles sold in Tyumen has tripled, and it is planned to develop bicycle-sharing for 1,000 bicycles in 2020-2021 [27].

The studies presented in this paper do not take into account the impact of the Coronavirus Covid-19 pandemic on urban mobility and the parameters of the functioning of the urban transport system. Paid parking creates prerequisites for not using personal vehicles. New bus lanes increase the speed of communication by land transport, and, consequently, make public transport more competitive and comfortable. Bike lanes increase the connectivity for cyclists and the demand for this mode of travel. The combined impact of limiting demand for private car travel and encouraging other modes of travel and walking shapes sustainable urban mobility.

Transforming urban transport systems in Moscow and St. Petersburg has identified a number of important features:

- restrictive measures on the travel of residents by car have led to an increase in demand for public transport, car-sharing services and taxis. As short-term car rental ('car sharing') services were developing in Moscow, the authorities allowed parking of 'car-sharing' cars 
in paid parking areas for free. As a result, there are virtually no free parking spaces in the centre of Moscow, and one of the goals of the development of the Unified Parking Space to create conditions for the availability of free parking spaces in the daytime was not achieved.

- as the demand for taxi services in the morning and evening grows, the 'aggregator' companies significantly increase their tariffs thus actually reducing the availability of this service and the quality of transport services for the population as a whole,

- low cost of parking can preserve the actual structure of mobility and have a negative social effect while preserving all the problems on the city roads.

Considering all the indicated features, municipal authorities need to apply an informed approach to the transformation of urban transport systems, obtaining objective information on the expected effects and its assessment in terms of possible consequences in the social, economic, environmental, and political life of the city. It is essential to find a balance between various groups of citizens with their diverse desires and opinions, between transport systems, the costs of developing infrastructure and the effect of its use.

Transport modelling was carried out in the PTV Visum program. The macroscopic transport model of the city with a population of 800 thousand people includes 400 transport regions. Transport modelling makes it possible to evaluate the change in the parameters of the urban transport system when the external and internal conditions affecting the system change [28-31]. By creating bus lanes and bike lanes in the transport model of the city, the resistance in the sections (sections of highways) for these transport systems is reduced. Therefore, the model reduces travel times on buses and bicycles. As the charge for parking in the city centre increases, resistance for personal vehicles increases in the model. To do this, parking fee is converted into time costs, taking into account the economic indicators for the city (the level of income of the population and the cost of paid parking).

Correspondences between transport areas by demand segments are allocated to different modes of transport (modes) using a cost matrix [32]. With a significant change in resistance of the transport systems, the transport demand is redistributed to other systems.

Nowadays, the model of people's transport behaviour is viewed as the distribution of the share of movements by transport modes for the existing city transport systems based on field observations. However, it does not integrate the main factors: income, the structure of expenses and the share of transport expenses of a household (family), social status and psychology of people, the age structure of the population, etc.

When developing transport planning documents for cities, separate studies are performed to establish how the level of development of transport (bus network, the number of bus stops) and road infrastructure (density of the road network, the length of roads, etc.) impacts the state of urban transport systems and urban mobility. Miscellaneous studies take into account the influence of some factors on population mobility. They view the transport system as a model of a 'black box' system and determine the dependence of the share of movements by modes and methods of transport on individual factors without taking into account the processes occurring in the system and the real connections between the elements of the system.

\section{RESULTS}

The structure of urban mobility can be divided into 4 travelling modes, which are considered in macroscopic transport models: private car, public transport, bicycles and walking. The share of each mode in the structure of urban mobility for a city with constant values of income of residents, cost of automobile fuel, state of the economy, demographic situation and 
structure of settlement is determined by a mathematical additive model based on the main effects and depends on 3 factors:

$$
\begin{gathered}
\Delta_{i}=\Delta_{i .0}+S_{1}\left(\mathrm{C}_{\mathrm{pp}}-\mathrm{C}_{\mathrm{pp} 0}\right)^{2}-S_{2} L_{\text {buslane }}-S_{3} L_{\text {bikelane }} \\
\sum_{i=1}^{n} \Delta_{i}=\Delta_{\mathrm{car}}+\Delta_{\mathrm{pt}}+\Delta_{\mathrm{ped}}+\Delta_{\text {bike }}=100 \%
\end{gathered}
$$

where $\Delta_{i 0}$ - share of private car, public transport, pedestrian and bike traffic under actual conditions; $C_{\mathrm{pp}}$ - private car parking cost, rub. per hour; $L_{\text {buslane }}$ - bus-only lanes length, $\mathrm{km}$; $L_{\text {bikelane }}$ - bike lane length, km; $S_{\mathrm{j}}$ - parameter of sensitivity to changes in the $j$ th factor.

All major cities in the world have gone through the problem of lack of parking spaces for private cars in the central areas. If there is an imbalance between the demand for free parking for cars and the number of parking lots, there are several options for actions on the part of residents:

- refusal to travel by car in favour of buses, taxis, car sharing, motorcycles, cycling vehicles, personal mobility devices (scooters, gyro scooters, etc.) or pedestrian travel,

- changing the time of travel to work to earlier or later,

- using paid parking, if available, within walking distance,

- using intercepting parking (if any) and completing the trip to the city centre by bus,

- violation of traffic and car parking rules (parking in courtyards of residential buildings, on sidewalks and lawns).

The nonlinear view of the dependence in Fig. 1 depends on the ratio of people's income and travel expenses on private transport, the availability of free parking in the walking distance, the presence of highly paid workers (the structure of the placement of jobs by areas of activity and income of employees) in the area of paid parking and others.

If the cost of parking a private car is low, the car owner will not refuse to use it. When the cost rises, and parking costs represent a significant share of the car owner's income, there will be an increase in refusals to travel to the paid parking area for full-day work purposes.

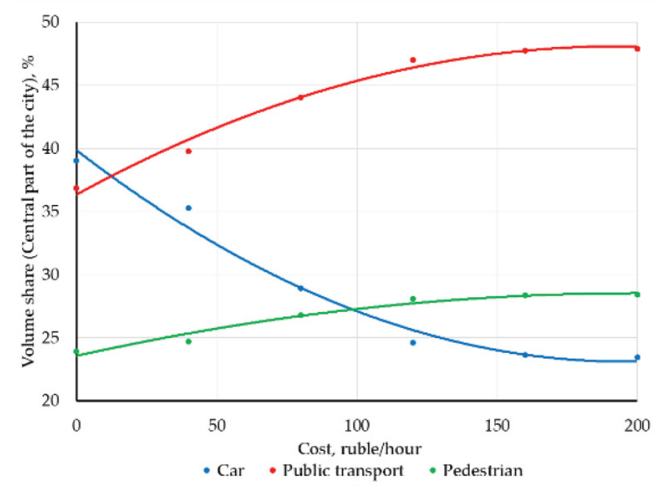

Figure 1: The impact of parking costs on the share of transfers to the paid parking area (central part of the city). 
Due to the peculiarities of macromodelling, an approach to a bus stop and a ride are counted as two independent movements, so the total number of correspondences to the city centre in the morning with an increase in the cost of parking increased from 45,570 to 47,416.

The greatest changes in the structure of urban mobility occur when the cost of $1 \mathrm{~h}$ of parking rises to 120 rubles. At the same time, there will not be a complete rejection of travel, since for a group of people with a large income, the cost of parking a car will not be critical. Also, travel to the city centre by taxi and car-sharing cars continues. With the additional demand for trips by public transport, the number of passengers transported on routes passing through the zone of paid parking change.

With the introduction of paid parking, the number of passengers getting off buses at the bus stops in the paid parking zone increases (Table 1). At the same time, the number of people who arrived at a given transport area with the terminal goal is significantly less than the number of passengers leaving the bus.

The rest of the passengers either change to another route, or go on foot to the place of work in another transport area. This is due to the peculiarity of the route network configuration and the absence of a tariff with payment on time and the possibility of transferring to another route without re-paying the fare. With a significant increase in passenger traffic at the bus stops, their reconstruction and an increase in the length of the bus stop platforms and overall dimensions of pavilions may be required.

In parallel with the creation of demand for public transport, it is necessary to improve the quality of passenger transportation, including through the development of bus lines.

The modelling results show that with an increase in the length of bus lanes from the existing 18 to $59 \mathrm{~km}$, the number of trips by public transport to the city centre increased by 350 trips in the morning (Fig. 2a). The number of trips by private cars decreased by 100 units (Fig. 2b). Additional demand for public transport is generated by pedestrians. The change in the number of trips in the city as a whole is more significant. With an increase in the length of bus lanes the number of trips by public transport to the city increased from 55,753 to 57,222 in the morning.

As the number of movements by bus in the morning increased, the passenger traffic at the bus stops in the city centre changed. The number of passengers getting off buses increased by $17.8 \%$. In parallel with the development of infrastructure for public transport, it is possible to develop infrastructure for cycling.

Important factors affecting the number of cycling trips are the length of bike lanes, the availability of bike parking lots and bike rentals.

In this study, in the transport model of the city, $91 \mathrm{~km}$ of bike lanes were created in the paid parking zone and in the direction towards it. The total length of bike lanes in the city model was $128 \mathrm{~km}$. With an increase in the length of bike lanes the number of trips by bicycle to the

Table 1: The number of passengers leaving public transport at the bus stops in the central part of the city in the morning

\begin{tabular}{lllll}
\hline \multirow{2}{*}{ Bus stop } & \multicolumn{4}{l}{ Number of passengers leaving, with and without paid parking, pers. } \\
\cline { 2 - 5 } & \multicolumn{2}{l}{ Moving on to the destination } & Arrived at the destination \\
\cline { 2 - 5 } & Free parking & Paid parking & Free parking & Paid parking \\
\hline Tsvetnoy bulvar & 810 & 833 & 104 & 234 \\
Skver Nemtsova & 1,199 & 1,812 & 399 & 1,148 \\
\hline
\end{tabular}


The number of movements in the city center by Bus, persons

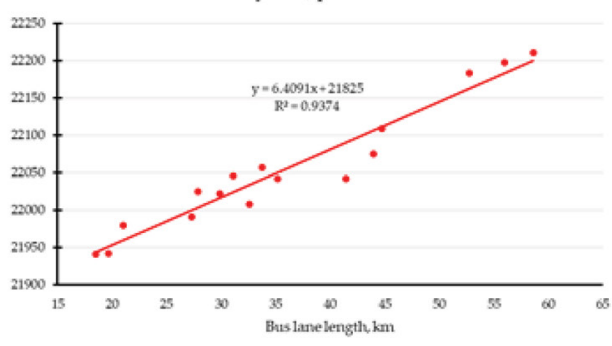

(a)

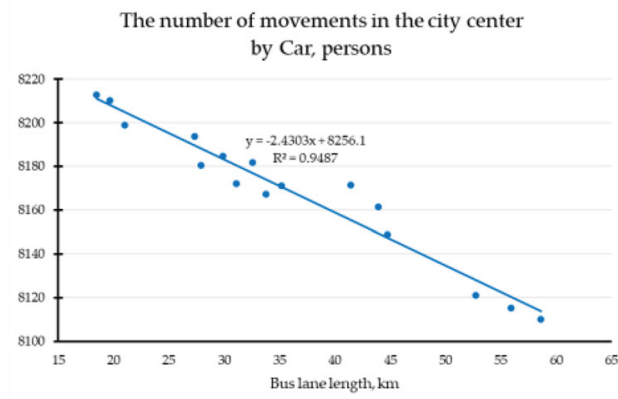

(b)

Figure 2: The influence of the length of bus lanes on the number of movements to the city centre (paid parking zone - the central part of the city, cost -120 rubles per hour): (a) by car; (b) by bus

Volume share (Central part of the city) by Bike, \%

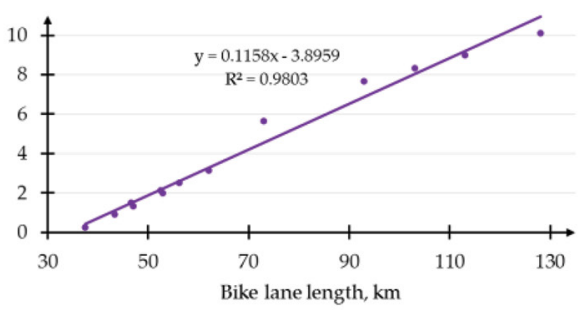

(a)
Volume share (City) by Bike, \%

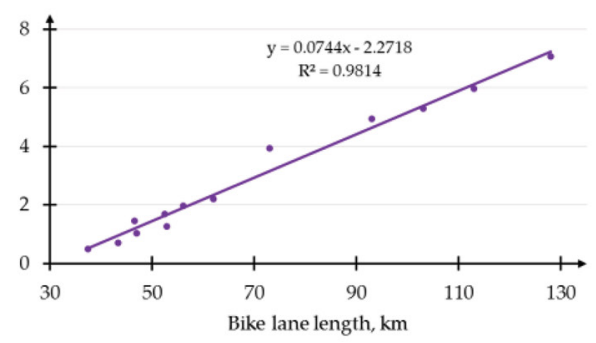

(b)

Figure 3: The influence of the length of bike lanes on the share of cycling trips (paid parking zone in the central part of the city, cost - 120 rubles per hour): (a) to the central part of the city; (b) in the city.

paid parking zone increased 12 times from 123 to 4,822 trips per day, and the share of travel by bike increased to $10.11 \%$ (Fig. 3a). The ultimate number of trips in the city as a whole is even higher (an increase to 10,305 trips), but it is increasing with a lower intensity under $7.07 \%$ (Fig. 3b). The share of trips by bike increased due to a decrease in the share of travels by private cars, public transport (Figs. 4a) and walking (Figs. 4b).

The number of passengers transported on certain bus routes and passenger traffic at the bus stops are decreasing. Most of all, the share of movements by bus and on foot decreases. This allows us to conclude that the development of cycling infrastructure alone will not reduce the number of trips by car significantly. To achieve sustainable urban mobility, a set of measures is required.

The problem of developing the cycling infrastructure in the cities of the Russian Federation is quite acute and differs in a number of features:

- under traffic rules movement of cyclists is allowed on public roads,

- when cyclists move on roads, there is a risk of accidents involving cyclists, 


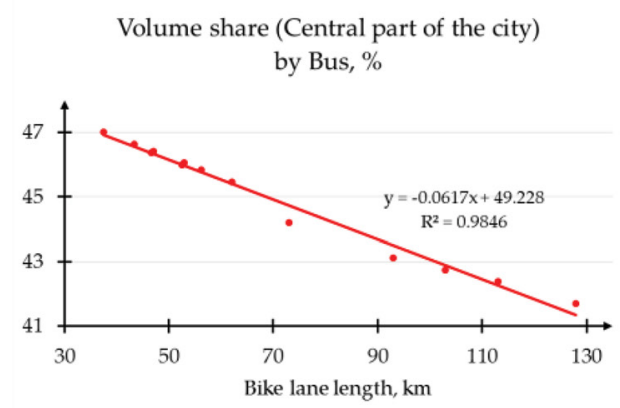

(a)
Volume share (Central part of the city) on foot, \%

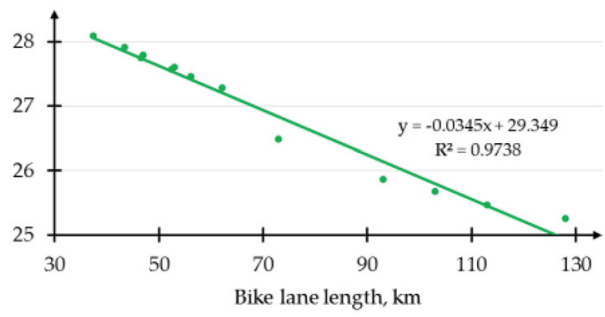

(b)

Figure 4: The influence of the length of bike lanes on the share of cycling trips (paid parking zone in the central part of the city, cost -120 rubles per hour): (a) by bus; (b) on foot.

- the Russia has little experience in designing modern infrastructure for cyclists,

- bike lanes in Russian cities are mainly created on sidewalks, reducing their width and worsening traffic conditions for pedestrians.

The data obtained were processed using correlation and regression analysis. For mathematical models of the demand structure in the central part of the city (eqn. (3)-(6)), the coefficient of factors influence (elasticity) has a higher value than in models for the city as a whole.

$$
\begin{aligned}
& \Delta_{\mathrm{car}}=44.03+0.00015\left(\mathrm{C}_{\mathrm{pp}}-\mathrm{C}_{\mathrm{pp} 0}\right)^{2}-0.022 L_{\text {buslane }}-0.025 L_{\text {bikelane }} \\
& \Delta_{\mathrm{pt}}=39.73-0.0001\left(\mathrm{C}_{\mathrm{pp}}-\mathrm{C}_{\mathrm{pp} 0}\right)^{2}+0.027 L_{\text {buslane }}-0.033 L_{\text {bikelane }} \\
& \Delta_{\text {ped }}=18.09-0.0000428\left(\mathrm{C}_{\mathrm{pp}}-\mathrm{C}_{\mathrm{pp} 0}\right)^{2}-0.0036 L_{\text {buslane }}-0.016 L_{\text {bikelane }} \\
& \Delta_{\text {bike }}=-2.13-0.0000019\left(\mathrm{C}_{\mathrm{pp}}-\mathrm{C}_{\mathrm{pp} 0}\right)^{2}-0.002 L_{\text {buslane }}+0.074 L_{\text {bikelane }}
\end{aligned}
$$

Changes in the structure of mobility for different options for the parking cost, lengths of lanes for buses and bikes are shown in Table 2. Changes in the city as a whole are less than in the central part of the city in the area of paid parking. Modelling shows that the municipal authorities of Tyumen will not be able to achieve the planned structure of mobility and the $44 \%$ share of bus movements only by introducing paid parking or creating bike lanes and bus lanes. A set of measures is required, possibly with the expansion of the paid parking zone.

The share of movements by modes of transport was calculated using the transport model developed for the city of Tyumen in 2018-2019. 
Table 2: Changes in the structure of mobility with different options for the parking cost, lengths of lanes for buses and bikes

\begin{tabular}{lccc}
\hline \multirow{2}{*}{$\begin{array}{l}\text { Share of travel by } \\
\text { modes and methods of } \\
\text { transport, \% }\end{array}$} & \multicolumn{3}{l}{ Options for combining parking costs, bus lanes and bike lanes } \\
\cline { 2 - 4 } & $\mathrm{C}_{\mathrm{pp}}=0 \mathrm{rub} / \mathrm{h}$ & $\mathrm{C}_{\mathrm{pp}}=200 \mathrm{rub} / \mathrm{h}$ & $\mathrm{C}_{\mathrm{pp}}=0 \mathrm{rub} / \mathrm{h}$ \\
$\mathrm{L}_{\text {buslane }}=18 \mathrm{~km}$ & $\mathrm{~L}_{\text {bikelane }}=37 \mathrm{~km}$ & $\mathrm{~L}_{\text {buslane }}=18 \mathrm{~km}$ & $\mathrm{~L}_{\text {bikelane }}=37 \mathrm{~km}$ \\
\hline City & $\mathrm{L}_{\text {bikelane }}=350 \mathrm{~km}$ \\
\hline Private cars & 48.82 & 43.25 & 35.9 \\
Buses & 34.8 & 39.15 & 31 \\
Bikes & 15.9 & 17.04 & 10.1 \\
Pedestrians & 0.48 & 0.56 & 23 \\
Total & 100 & 100 & 100 \\
\hline & 40 & Central part of the city & 24.8 \\
\hline Private cars & 40 & 23 & 25.1 \\
Buses & 35.9 & 47.89 & 14.1 \\
Bikes & 23.9 & 28.7 & 36 \\
Pedestrians & 0.2 & 0.41 & 100 \\
Total & 100 & 100 & \\
\hline
\end{tabular}

Economic parameters in this model are:

- average salary of a city resident $-47,000$ rubles.

- bus fare -24 rubles.

- fuel cost -43 rubles per liter.

An important factor affecting transport mobility is the area of the city where paid parking has been introduced. The high cost of parking in a small area may not have the effect of reducing the proportion of movements by car. Conversely, the expansion of the paid parking zone at a 'reasonable cost' may affect the share of movement in the city as a whole, and not just in the central part of it. The boundaries of the paid parking area for private cars in the Tyumen city model varied from $10 \%$ to $50 \%$ of the area of the central planning area. The change in the structure of population mobility during the phased introduction of paid parking and the creation of bus lanes and bike lanes is shown in Fig. 5 .

As we can see from the graphs, with the expansion of the paid parking zone, the share of movements by car decreases, while by bus and on foot - increases. The largest changes in the structure of demand occur in the city centre in the zone of paid parking. The changes in the whole city are less significant.

For Tyumen, there is a problem of insufficient connectivity of areas and non-straightness of traffic routes due to the presence of natural (the River Tura) and artificial obstacles (TransSiberian railway) on the territory of the city. This is especially true in the central part of the city, where there is an intense movement of private and public transport on existing bridges. In 2020, work began on the design of a new pedestrian bridge in the city centre. 


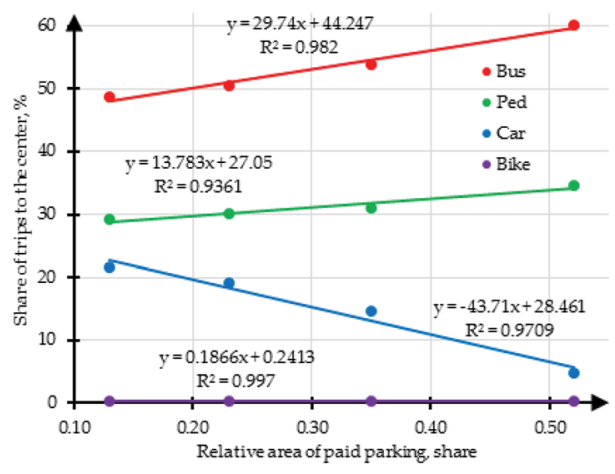

(a)

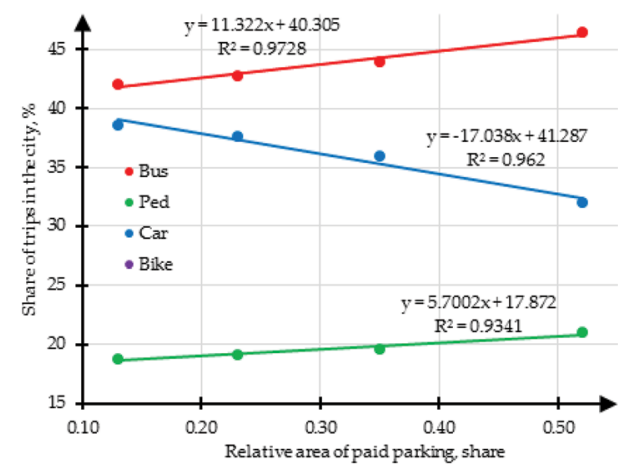

(b)

Figure 5: The influence of the relative area of paid parking on the share of movements (cost -120 rubles per hour): (a) in the city; (b) to the central part of the city.

Table 3: Traffic intensity on the pedestrian bridge (per day)

\begin{tabular}{lccr}
\hline & \multicolumn{2}{l}{$\begin{array}{l}\text { Number of pedestrians on the bridge, } \\
\text { pers. }\end{array}$} & \\
\cline { 2 - 3 } Pedestrian traffic direction & $\begin{array}{l}\text { Without bus routes } \\
\text { No. 1, } 2\end{array}$ & $\begin{array}{l}\text { With bus routes } \\
\text { No. 1, 2 (10-min } \\
\text { headway) }\end{array}$ & \\
\hline To the part of the city across the river & 2,040 & 6,412 & by 3.14 \\
To the central part of the city & 402 & 4,372 & by 10.87 \\
Total & 2,442 & 10,784 & by 4.41 \\
\hline
\end{tabular}

The work considers the issues of pedestrian traffic with work-related, educational, cultural or domestic purposes and does not consider recreational walking. The construction of a new pedestrian bridge improves the connection between the two parts of the city. The historical and business centre of the city is located on the high bank of the river. A new housing block is being built on the low bank. For residents of the housing block, the walking route to the city centre is reduced by $0.7 \mathrm{~km}$ due to its straightness.

The simulation results show that the predicted intensity of pedestrian traffic on the new bridge during the day is small and amounts to 2,442 people (Table 3). At the same time, the main pedestrian flow moves to the part of the city situated on the other side of the river 2,040 people, and much less to the city centre -402 people.

This is due to the fact that residential buildings are located directly near the river bank in the city centre and there are no large centres of attraction for people. Therefore, the intensity of pedestrian traffic on the bridge to the city centre is low. The large number of pedestrians going to the part of the city situated on the other side of the river is explained by the construction there not only of residential buildings, but also premises for business and the creation of 5,760 jobs.

The pedestrian bridge creates an opportunity to shorten the length of the route for residents of the area situated on the other side of the river, who travel by public transport to the western part of the city district and save time for the implementation of transport correspondence by 
13-15 min. To do this, it is necessary to create a stopping point in the central part of the city near the pedestrian bridge and adjust the route network. The distance to the new bus stop increases on average by $100-150 \mathrm{~m}$.

The paper formulates a hypothesis that when new bus routes and a bus stop near the pedestrian bridge are created, the intensity of pedestrian traffic on the bridge will increase in order to approach the bus stop and further movement by bus with a work purpose to the western and southern parts of the city. This will result in a redistribution of demand between individual bus routes. To test the hypothesis in the transport model of the city, two new bus routes were created to the south-western and southern parts of the city. The bus headway was taken as 10 , 20 and $30 \mathrm{~min}$.

With the integrated development of infrastructure for buses and pedestrians, the intensity of movement of people across the new bridge increases significantly by 4.41 times (Table 3 ). In the direction to the city centre, the number of pedestrians on the bridge increased by 10.87 times, to the city area situated on the other side of the river - by 3.14 times. The intensity of pedestrian traffic across the bridge to the city centre in the morning increased from 83 to 609 people, from the centre to the city area situated on the other side of the river - from 199 to 477 people.

With shorter bus headways, the demand for trips by bus on new routes, passenger traffic at a new bus stop (Table 4) and the intensity of pedestrian traffic on the bridge increase (Table 5). With a decrease in the headway from 30 to $10 \mathrm{~min}$, the number of pedestrians on the bridge moving to the centre increased by $9.6 \%$, and to the city area across the river - by $6.1 \%$. It also proves the impact additional bus routes have on the pedestrian traffic on the bridge.

The number of passengers entering buses at the 'ul. Alebashevskaya' stop decreased by $30 \%$ from 2,437 to 1,701 people. These passengers chose the new footbridge and new bus

Table 4: Daily passenger exchange of the new bus stop 'Peshekhodnyy most'.

\begin{tabular}{lccc}
\hline \multirow{2}{*}{ Indicator } & \multicolumn{3}{l}{$\begin{array}{l}\text { Passenger traffic of the new bus stop, pers. at bus headways on } \\
\text { routes 1 and 2 }\end{array}$} \\
\cline { 2 - 4 } & $10 \mathrm{~min}$ & $20 \mathrm{~min}$ & $30 \mathrm{~min}$ \\
\hline Passengers entering & 5,888 & 5,635 & 5,403 \\
Passengers leaving & 6,311 & 4,974 & 4,766 \\
Total & 12,199 & 10,609 & 10,169 \\
\hline
\end{tabular}

Table 5: Traffic intensity on the pedestrian bridge (per day) when changing the headway of new bus routes

\begin{tabular}{lccc}
\hline \multirow{2}{*}{ Pedestrian traffic direction } & \multicolumn{3}{l}{$\begin{array}{l}\text { Number of pedestrians, pers. at bus headways on } \\
\text { routes 1 and 2 }\end{array}$} \\
\cline { 2 - 4 } & $10 \mathrm{~min}$ & $20 \mathrm{~min}$ & $30 \mathrm{~min}$ \\
\hline To the part of the city across the river & 6,618 & 6,412 & 6,239 \\
To the central part of the city & 4,609 & 4,372 & 4,205 \\
Total & 11,227 & 10,784 & 10,444 \\
\hline
\end{tabular}


routes. A decrease in this indicator also occurred at other bus stops in the part of the city situated on the other side of the river.

Conclusions on the results of modelling pedestrian traffic on the new bridge:

- the appearance of a new pedestrian and transport infrastructure in the city creates a transport demand for its operation

- adding convenient bus routes to the new pedestrian bridge increases the demand for traffic on the pedestrian bridge

\section{DISCUSSION}

The results of the research show that it is very difficult to achieve a significant change in the structure of urban mobility only by stimulating measures. A set of demotivating measures aimed at users of private cars is required. The introduction of parking fees has a significant impact on the structure of urban mobility.

The maximum improvements in traffic parameters, an increase in passenger traffic at the bus stops and an increase in the number of public transport passengers are noted in the area of paid parking and on bus routes passing through the city centre. In the peripheral areas of the city, the change in the indicators is insignificant.

Thus, mobility management by regulating the cost of parking and the number of parking spaces gives an initial impetus to achieve a balanced structure of urban mobility corresponding to the level of development of transport infrastructure.

Further changes in the structure of urban mobility can be achieved by increasing the length of lanes for buses and bikes, improving the quality of passenger transportation, developing of bike rentals, preferential rates or free bus travel, etc.

\section{CONCLUSIONS}

The theoretical and experimental studies carried out by the authors made it possible to establish the patterns of the influence of the cost of paid parking, the length of the lanes for buses and bikes on the structure of the city's urban mobility. The application of the established patterns allows us to formulate recommendations for achieving the optimal structure of urban mobility. This will improve the balance and sustainability of urban transport systems, taking into account their characteristics.

Improving the quality of transport services requires additional financial and material costs. However, a decrease in the number of movements by private cars will reduce the costs of developing the road network over time. A decrease in the number of cars on highways will improve the technical and operational performance of the rolling stock of buses and the remaining cars, improve the quality of passenger traffic on highways that do not have dedicated bus lanes.

It is highly likely that if the coronavirus Covid-19 pandemic lasts long enough, the economic situation will worsen, and the proportion of people working from home will increase. This will lead to a decrease in transport demand and load on the city's transport system. To maintain the social distance of $1-1.5 \mathrm{~m}$ on a bus, it will be necessary to increase the quantity of rolling stock or replace it with more spacious vehicles. This is not possible, since large financial costs will be required at once. New conditions will require calibrating urban transport models and establishing new patterns. 


\section{ACKNOWLEDGEMENTS}

The article was prepared as part of the implementation of a state assignment in the field of science for scientific projects carried out by teams of researchers in scientific laboratories of higher educational institutions subordinate to the Russian Ministry of Education and Science on the project: 'New patterns and solutions for the functioning of urban transport systems in the paradigm 'Transition from owning a personal car to mobility as a service"' (No. 08252020-0014, 2020-2022).

\section{REFERENCES}

[1] Currie, G. \& De Gruyter, C., Exploring links between the sustainability performance of urban public transport and land use in international cities. Journal of Transport and Land Use, 11, pp. 325-342, 2018. doi:10.5198/jtlu.2018.957.

[2] Mohan, D. \& Tiwari, G., Sustainable transport systems: linkages between environmental issues, public transport, non-motorised. Economic and Political Weekly, 34(25), pp.1589-1596, 1999.

[3] Keay, K. \& Simmonds, I., The Association of Rainfall and Other Weather Variables with Road Traffic Volume in Melbourne, Australia. Accident Analysis and Prevention, 37, pp. 109-124, 2005. doi.org/10.1016/j.aap.2004.07.005.

[4] Diao, M., Towards sustainable urban transport in Singapore: policy instruments and mobility trends. Transport Policy, 81, pp. 320-330, 2019. doi.org/10.1016/j. tranpol.2018.05.005.

[5] Schoeman, C.B.; Schoeman, I.M. Land use, traffic generation and emissions in formulating a simplified approach in assessing development impacts in residential areas. International Journal of Transport Development and Integration, 3(2), pp. 166178, 2019. doi.org/10.2495/TDI-V3-N2-166-178.

[6] Calculation of the efficiency of MaaS solutions (mobility as a service - mobility as a service) using PTV MaaS Modeller. https://www.ptvgroup.com/ru/reshenija/produkty/ ptv-maas-modeller (accessed on 20 August 2020).

[7] Noy, K. \& Givoni, M., Is 'smart mobility' sustainable? Examining the views and beliefs of transport's technological entrepreneurs. Sustainability (Switzerland), 10(2), 422, 2018. doi.org//10.3390/su10020422.

[8] Parkhurst, G., Influence of bus-based park and ride facilities on users' car traffic. Transport Policy, 7 (2), pp. 159-172, 2000. doi.org/10.1016/S0967-070X(00)00006-8.

[9] Pucher, J.; Dill, J. \& Handy, S., Infrastructure, programs, and policies to increase bicycling: an international review. Preventive Medicine, 50, Issue SUPPL., January 2010, S106-S125. doi.org/10.1016/j.ypmed.2009.07.028.

[10] Nistor, M.; Dias, A., Bike distribution model for urban data applications. International Journal of Transport Development and Integration, 3(1), pp. 67-78, 2019. doi. org/10.2495/TDI-V3-N1-67-78.

[11] Dingil, A.E.; Rupi, F.; Stasiskiene, Z., A macroscopic analysis of transport networks: the influence of network design on urban transportation performance. International Journal of Transport Development and Integration, 3(4), pp. 331-343, 2019. doi. org/10.2495/TDI-V3-N4-331-343.

[12] Cengiz, E.C., Bus rapid transit: an environmental friendly transport solution for Istanbul. International Journal of Transport Development and Integration, 1(1), pp. 54-62, 2017. doi.org/10.2495/TDI-V1-N1-54-62. 
[13] Van Ommeren, J. N.; Wentink, D. \& Rietveld, P., Empirical evidence on cruising for parking. Transportation Research Part A: Policy and Practice, 46, pp. 123-130, 2012. doi.org/10.1016/j.tra.2011.09.011.

[14] Wilson, R.W. \& Shoup, D.C., Parking subsidies and travel choices: assessing the evidence. Transportation, 17, pp. 141-157, 1990. doi.org/10.1007/BF02125333.

[15] Wilson, R.W., Estimating the travel and parking demand effects of employer-paid parking. Regional Science and Urban Economics, 22 (1), pp. 133-145, 1992. doi. org/10.1016/0166-0462(92)90029-Z.

[16] Sargisson, R.J., Do parking fees affect commuting choices of staff and students on a university campus? International Journal of Transport Development and Integration, 2(2), pp. 189-201, 2018. doi.org/10.2495/TDI-V2-N2-189-201.

[17] Thomas, T.; Jaarsma, R. \& Tutert, B., Exploring temporal fluctuations of daily cycling demand on Dutch cycle lanes: the influence of weather on cycling. Transportation, 40(1), pp. 1-22, 2013. doi.org/10.1007/s11116-012-9398-5.

[18] Hamre, A. \& Buehler, R., Commuter mode choice and free car parking, public transportation benefits, showers/lockers, and bike parking at work: evidence from the Washington, DC Region. Journal Public Transportation, 17, pp. 67-91, 2014. doi:10.5038/2375-0901.17.2.4.

[19] Rodríguez, D.A.; Levine, J.; Agrawal, A. W. \& Song J., Can information promote transportation-friendly location decisions? A simulation experiment, Journal of Transport Geography, 19(2), pp. 304-312, 2011. doi.org/10.1016/j.jtrangeo.2010.04.001.

[20] Rosa, M.P.; Gameiro, C.; Sousa, C.; Pinto, P.C., An analysis of elderly tourists' constraints in the use of public transport. International Journal of Transport Development and Integration, 4(2), pp. 163-178, 2020. doi.org/10.2495/TDI-V4-N2-163-178.

[21] Zakharov, D. \& Fadyushin, A., "Changes in the structure of urban mobility with the development of infrastructure for public transport and cyclists in cities" WIT Transactions on Built Environment, Vol 200, WIT Press, 2020, ISSN 1743-3509

[22] Zhang, Y., Thomas, T., Brussel, M.J.G., Van Maarseveen, M.F.A.M. The characteristics of bike-sharing usage: case study in Zhongshan, China. International Journal of Transport Development and Integration, 1(2), pp. 245-255, 2017. doi.org/10.2495/ TDI-V1-N2-245-255.

[23] Tatum, K., Parnell, K., Cekic, T.I., Knieling, J., Driving factors of sustainable transportation: satisfaction with mode choices and mobility challenges in Oxfordshire and Hamburg. International Journal of Transport Development and Integration, 3(1), pp. 55-66, 2019. doi.org/10.2495/TDI-V3-N1-55-66.

[24] Esztergár-Kiss, D. \& Kerényi, T., Creation of mobility packages based on the MaaS concept. Travel Behaviour and Society, 21, pp. 307-317, 2020. doi.org/10.1016/j. tbs.2019.05.007.

[25] Karlsson, M.I.C., Sochor, J. \& Strömberg, H., Developing the 'service' in mobility as a service: experiences from a field trial of an innovative travel brokerage. Transportation Research Procedia, 14, pp. 3265-3273, 2016.

[26] Petrov, A. \& Petrova, D., Sustainability of Transport System of Large Russian City in the Period of COVID-19: Methods and Results of Assessment. Sustainability, 12(18), 7644, 2020. doi.org/10.3390/su12187644.

[27] Tyumen region today. In Tyumen, the number of bicycles for rent will increase to 600 . Available online: https://tumentoday.ru/2020/09/12/spros-na-veloshering-v-tyumeniprevzoshel-vse-ozhidaniya/ (accessed on 20 November 2020). 
[28] Schoeman, C.B., International perspectives on transportation and urban form integration. International Journal of Transport Development and Integration, 1(1), pp. 1-15, 2017. doi.org/10.2495/TDI-V1-N1-1-15.

[29] Jacyna, M., Wasiak, M., Kłodawski, M., Gołębiowski, P., Modelling of Bicycle Traffic in the Cities Using VISUM. Procedia Engineering, 187, pp. 435-441, 2017. doi. org/10.1016/j.proeng.2017.04.397.

[30] Arliansyah, J., Prasetyo, M.R., Kurnia, A.Y., Planning of city transportation infrastructure based on macro simulation model. International Journal on Advanced Science, Engineering and Information Technology, 7(4), pp. 1262-1267, 2017. doi. org/10.18517/ijaseit.7.4.2444.

[31] Ramli, M.I., Runtulalo, D., Yatmar, H., Mangessi, A., An Estimation of OriginDestination Matrices for a Public Transport Network in Makassar using Macrosimulation Visum. IOP Conference Series: Materials Science and Engineering 875(1), 012027, 2020. doi.org/10.1088/1757-899X/875/1/012027.

[32] PTV AG, PTV Visum Manual. Available online: http://cgi.ptvgroup.com/vision-help/ VISUM_18_ENG/ (accessed on 23 July 2020). 